\title{
Laparoscopic Subtotal Hysterectomy: Does It Still have a Stand?
}

\author{
${ }^{1}$ Liselotte Mettler, ${ }^{2}$ Ibrahim Alkatout
}

\begin{abstract}
Classic intrafascial subtotal hysterectomy $(\mathrm{CISH})$ technique is one method of intrafascial supracervical or subtotal hysterectomy that was performed by laparoscopy in Kiel, Germany, from 1989 until 2005 and has then been replaced by laparoscopic subtotal hysterectomy (LASH) or (LSH) technique, we intend to give in this article a review on both valuable technologies. Many clinicians do not like subtotal hysterectomy at all; however, in our time of understanding that less might be more effective than more for some patients, we are happy to stress the fact of this surgical technology and are giving the background of its development.
\end{abstract}

Keywords: Classic intrafascial subtotal hysterectomy, Laparoscopic subtotal hysterectomy.

How to cite this article: Mettler L, Alkatout I. Laparoscopic Subtotal Hysterectomy: Does It Still have a Stand? Int J Gynecol Endsc 2018;2(1):22-28.

Source of support: Nil

Conflict of interest: None

\section{INTRODUCTION}

Subtotal hysterectomy, first performed by Freund, ${ }^{1}$ was the leading technique of hysterectomy for over 80 years until Tervilä ${ }^{2}$ described the danger of cervical cancer as 0.3 to $1.9 \%$ following supracervical hysterectomy. From 1950 onward, hysterectomy was performed almost exclusively as total hysterectomy until Semm revived interest in supracervical hysterectomy in the 1990s by introducing the CISH technique to be performed by pelviscopy and laparotomy ${ }^{3-10}$ with coring of the inner cervix. Other major contributions to this technique soon followed. ${ }^{11,12}$

\section{MATERIALS AND METHODS}

\section{Classic Intrafascial Supracervical Hysterectomy}

The CISH technique, as one method of supracervical or subtotal hysterectomy, was performed in Kiel

\footnotetext{
${ }^{1}$ Professor Emeritus, ${ }^{2}$ Priv. Doz.

1,2Department of Obstetrics and Gynecology, University Clinics of Schleswig-Holstein, Kiel, Germany
}

Corresponding Author: Liselotte Mettler, Professor Emeritus Department of Obstetrics and Gynecology, University Clinics of Schleswig-Holstein, Kiel, Germany, e-mail: profmettler@gmx.de from 1989 until 2005 but was then replaced by LASH technique.

To exclude the possible development of a cervical stump malignancy in the cervical functional tissue, the transformation zone was resected by transvaginal cylindrical coring of the cervical tissue using a 15, 20, or $24 \mathrm{~mm}$ Calibrated Uterine Resection Tool (CURT). This coring involved transvaginal excision of the functional cervical tissue from the muscular and connective tissue components of the uterine cervix. To ensure the safety of this excision without endangering ureters or the uterine artery, it was necessary to manipulate the uterus which normally lies in ante- or retroflected position into a straight position. This was done by introducing a $5 \mathrm{~mm}$ perforation rod into the external cervical os and pushing it through the internal os into the cavity and finally perforating the uterus in the middle of the fundus. Even in cases of large uterine fibroids, it was possible to find the uterine cavity. The device for coring out of a tissue cylinder is demonstrated in Figure 1. Once a straight line has been established between the cervical canal and the uterine fundus, a preselected CURT may be applied over the perforation rod to cut out the appropriate cylinder leaving the cervical outer shell intact. Four steps characterize the technique, two from the vaginal side and two transabdominally. We describe these steps as a historical development only but proceed with the LASH technique which is internationally called LSH (laparoscopic subtotal hysterectomy).

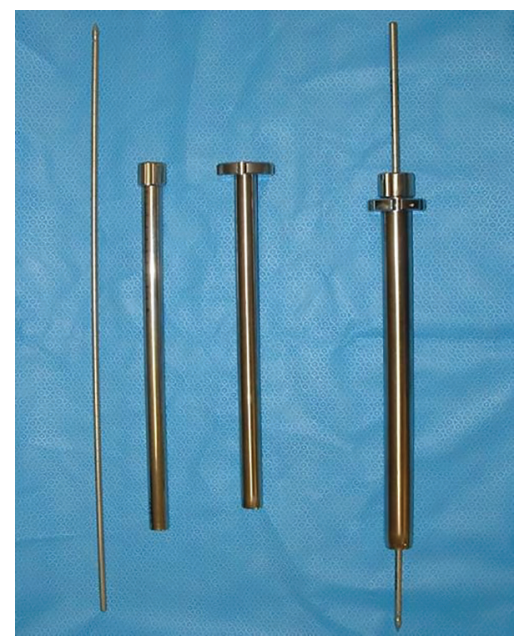

Fig. 1: The CURT along the previously placed axial guide as first and second vaginal steps of $\mathrm{CISH}$ 


\section{First Vaginal Step}

Preoperatively, the vagina is disinfected; the cervix is grasped at 3 and 9 o'clock by two tenacula. Following this, the uterus length is measured, the cervical canal is dilated up to Hegar 5, and the $50 \mathrm{~cm}$ long perforation rod is introduced into the uterus according to the uterine length. The perforation rod is part of the CURT set and is fixed vaginally together with two tenacula using a specifically designed clamp and screw. With large uterine fibroids, this can be difficult and is sometimes more easily performed following transsection of the supracervical uterus. The correct diameter of the CURT is selected based on the ultrasound measurement of the cervix and upon inspection. The proper selection of CURT is important because if the cylinder is too wide, it would cut outside the cervical fascia. A cylinder that is too narrow would not remove all of the functional cervical tissue. The center of fixation of the uterus allows for a three-dimensional maximal mobilization of the uterus transvaginally. During this procedure the uterus is continually observed on the video screen.

\section{First Laparoscopic Step}

After having established a clear endoscopic view into the pelvis with no bowels adherent to the structures of the uterus, the perforation of the uterine fundus is performed under vision. The uterus can now be anteverted, retroverted, and lateralized.

The adnexa are separated from the pelvic side wall using ligatures, sutures, staplers, ligasure, ultrasound, or whatever hemostatic technique is available. Separation of the adnexa usually causes a minimal blood loss. The round ligament is also coagulated and divided. This dissection of the adnexa and round ligament leads to an opening of the vesicovaginal fold and to an opening of the posterior leaf of the broad ligament.
The first laparoscopic part of CISH consists of the following steps:

- Separation of adnexa and round ligament from pelvic side wall or uterus

- Dissection of the vesicouterine peritoneum, opening of the paravesical space

- Placement of one cervical loop

After having exposed the cervix, a Roeder polydioxanone (PDS) loop is loosely placed around the cervix ready to be locked after the CURT cylinder is resected to prevent gas leakage.

\section{Second Vaginal Step}

The fixing screw holding the axial guide rod of the CURT is removed. The cutting tube around the central cylinder is placed as a unit over the axial guide rod and the chosen cylinder is cored out electrically under endoscopic vision. The tenacula placed at 3 and 9 o'clock are gently pulled and the motor drive is slowly advanced. An equal pressure is applied to the cutting tube as it is rotated and advanced from the cervix through the endometrium to the fundus. As the cutting tube advances, the calibrated scale along the central cylinder slowly reveals the depth of tissue already cut (Fig. 2).

The cutting tube is rotated and slowly cores out a cylinder through the fundal serosa. It is important to ensure that each last thread of tissue has been cut; otherwise, the tissue cylinder cannot be removed transvaginally.

After the tissue cylinder has been completely cored out, it is carefully withdrawn and extracted through the vagina under transabdominal laparoscopic control. The endocervical wound is coagulated up to a maximum of $2.5 \mathrm{~cm}$ into the resection canal. After the CURT cylinder has been resected, there is very little bleeding; however, as a prophylaxis against later bleeding the inner part of the remaining cervical cylinder has to be coagulated, preferably with an endocoagulator at $120^{\circ} \mathrm{C}$ or with bipolar
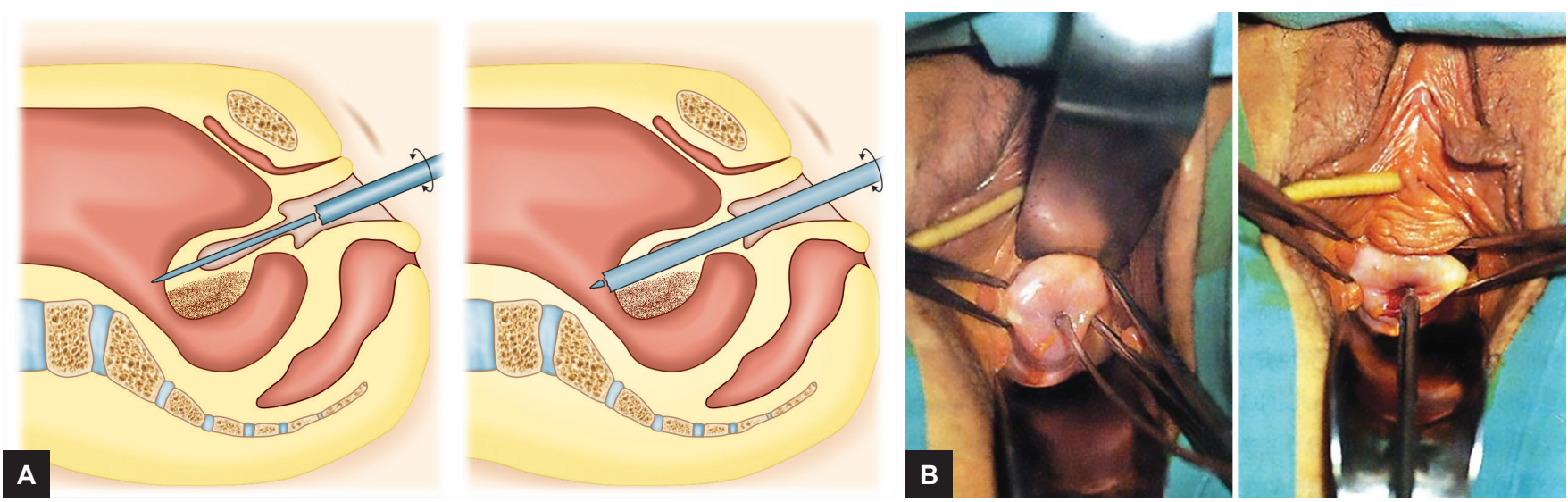

Figs 2A and B: First vaginal step of $\mathrm{CISH}$. (A) Positioning of CURT. (B) Anatomical situation with grasping the cervix at 3 and 9 o'clock and measuring the length of the cervix, introduction of the axial guide of CURT 

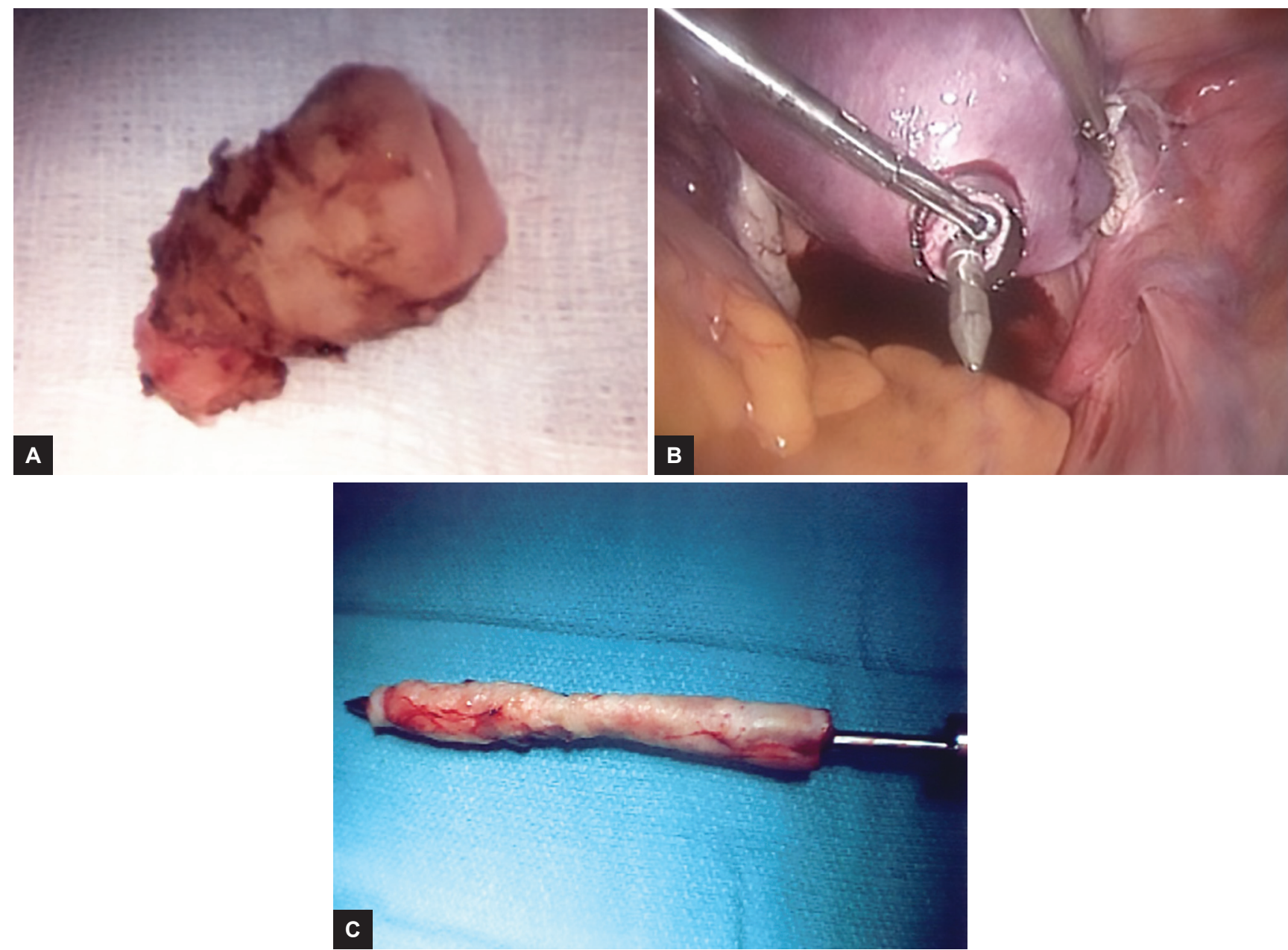

Figs 3A to C: (A) Resected specimen at additional conization (which was rarely indicated). (B) Anatomical situation of coring of the inner cervix. (C) Cored-out specimen for pathohistological examination

coagulation forceps. Figures 3 and 4 demonstrate the preparatory and two transvaginal surgical steps.

\section{Second Laparoscopic Step}

With a $10 \mathrm{~mm}$ claw forceps, the uterus is grasped and pulled in the direction of the umbilicus. The prepositioned Roeder loop is placed as deep as possible and closed similar to a tourniquet around the cervix (Figs 5 and 6).

This technique was already recommended by Rubin in 1951 as a temporary ligature around the ascending branches of the uterine artery for myoma enucleations.

The double cervical ligature: A subsequent ligature is placed over the cervix to closely tie the ascending branches of the uterine artery and its collaterals. If the ligature is not set tightly enough, it is possible that after resecting the uterus, the fascial tissue could invaginate and loosen the ligatures securing the uterine arteries.

Resecting the uterus: When the pericervical fascial tissue has been ligated using the double-loop ligation technique, the uterus is regrasped with the forceps and pulled in the direction of the umbilicus. It may then be resected with a monopolar loop above the ligatures, with

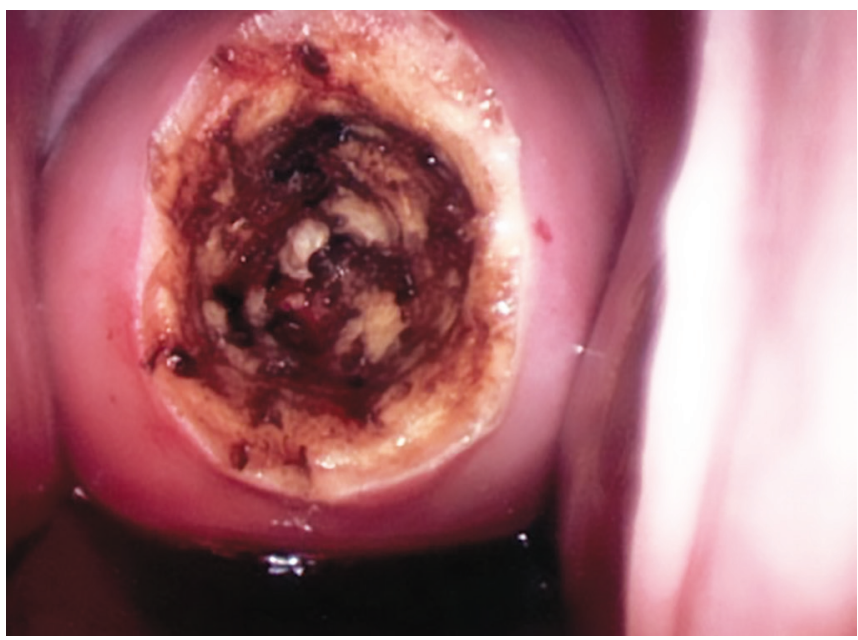

Fig. 4: Coagulation of cored-out cervix

hook scissors, a laser, or a monopolar current hook. The remaining stump should be at least 2 to $3 \mathrm{~cm}$.

Sterilization of the intraabdominal cervical stump: Disinfection is performed with iodine and the bipolar forceps are applied to coagulate the surface of the stump. 

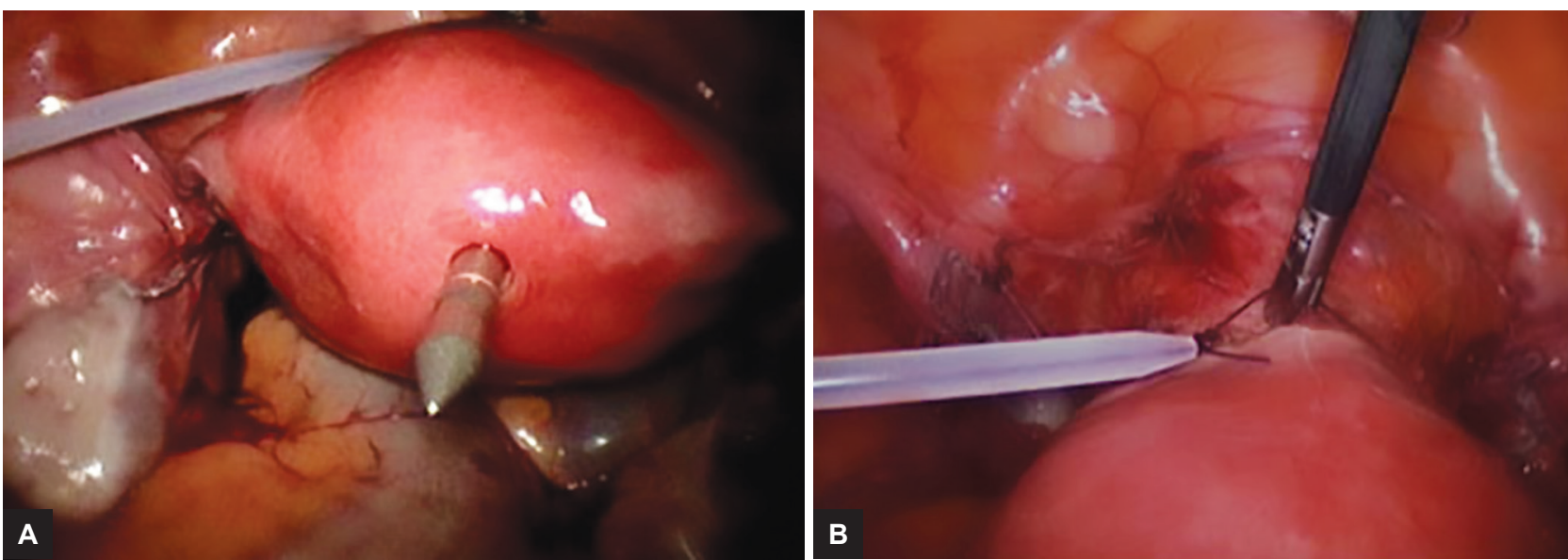

Figs 5A and B: Ligation of uterine cervix with two PDS Roeder loops
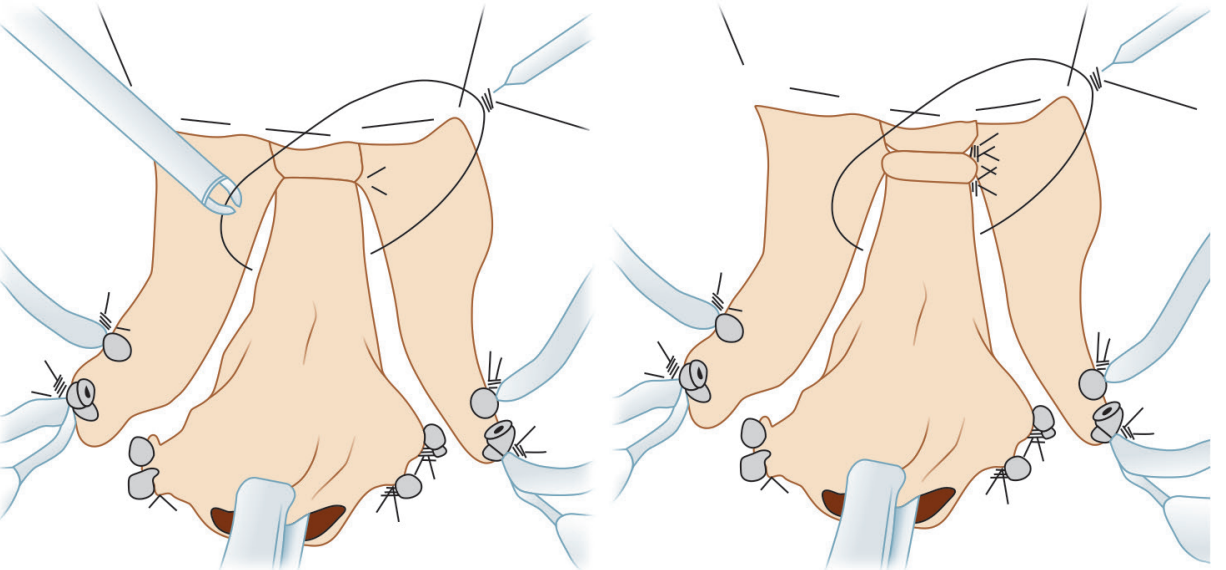

Fig. 6: Schematic illustration of loop placement at $\mathrm{CISH}$

Peritonealization: When the cervical stump clearly shows the ascending branches of the uterine artery, these may be coagulated and the tourniquet released. The two remaining PDS threads are not a hindrance. The stump may be covered by placing the vesicouterine peritoneum over the tissue pedicles (Fig. 7).

The pelvis is then irrigated with 1 to $2 \mathrm{~L}$ of Ringer's lactate and a careful supervision of the whole abdomen is carried out.

Morcellation of the uterus: The large claw forceps grasps the uterus which is then morcellated from the left lateral incision point through the morcellator. We usually dilate up to the required morcellator size. The Storz Rotocut is ideal for this purpose. For further hemostasis and adhesion prevention, the remaining cervical stump is coagulated with the bipolar forceps.

The second laparoscopic part of CISH consists of the following steps:

- Closing of two ligatures around the cervix

- Separation of cervix from uterus

- Coagulation of cervical stump

- Morcellation

- Peritonealization of stump

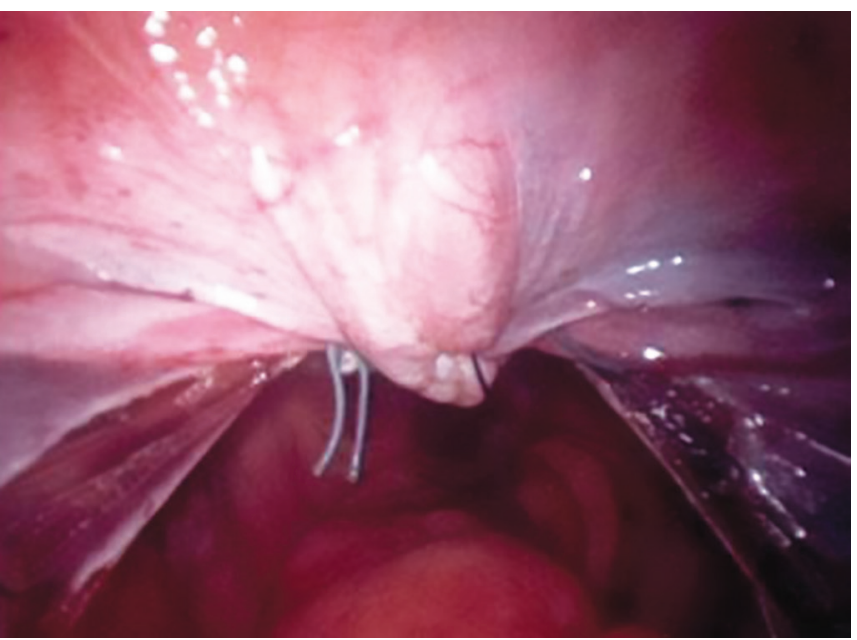

Fig. 7: Peritonealization after $\mathrm{CISH}$

Histopathology of CISH specimens: A normal nonelongated cervix measures 2.5 to $3 \mathrm{~cm}$ in length. It is separated into an ectocervix and an endocervix. The ectocervix is covered with stratified squamous epithelium. The epithelium changes from ecto to endocervix, from a squamous epithelium to columnar epithelium. The 
epithelium is quite granular and in the area of the endocervix the so-called endocervical glands may be found.

The cervical sections are analyzed as to whether a hyperplastic cervical mucosa is present and for remaining glandular components. The distal cervical segment, as it progresses to the isthmus, is analyzed in cross sections. This is performed to demonstrate the outer circumference of the cervix and to allow the pathologist to check for possible mesonephric duct remnants. The uterine cavity segment is also sectioned in a longitudinal manner. The procedure allows for an absolutely correct and accurate histopathological assessment of all the uterine tissue.

The individual steps of the laparoscopic CISH technique are summarized in Figures 3 to 6.

\section{RESULTS AND DISCUSSION}

Experience with CISH now dates back to 1990. The technique is easy to perform, can be carried out on smaller and larger uteri, and leaves the pelvic floor intact. It has a short rehabilitation time and high patient acceptance. It is very cost-effective and has a low complication rate. ${ }^{13-17}$

The CISH technique is an advanced laparoscopic procedure that is initially technically challenging but has a quick learning curve. It can be easily performed by two surgeons with three hands for the surgery and one hand to hold the camera. Every evaluation postulates that patients undergoing laparoscopic supracervical hysterectomy compared with total hysterectomy have shorter operation times, shorter hospital stays, and less morbidity than those who underwent laparoscopic-assisted vaginal hysterectomy or total laparoscopic hysterectomy. ${ }^{18}$ The practice of routine cervicectomy at laparoscopic hysterectomy should be reconsidered. Okara et $\mathrm{al}^{16}$ published data related to the cervical stump requiring further surgery following a laparoscopic supracervical hysterectomy. These data, however, could not be verified in our own retrospective evaluation ${ }^{13,19}$ nor in data published by colleagues using the LASH technique. ${ }^{20,21}$ The LASH technique is an easier surgical method than $\mathrm{CISH}$ and fulfils the same purpose. Thus, CISH can be considered a simple subtotal hysterectomy. It has all the advantages of a subtotal hysterectomy and additionally includes the coring of the inner cervix. ${ }^{17}$ This prevents the occurrence of cervical stump cancer which after CISH only appears in 1 of 5 million cases.

Surgical complications and clinical outcome proved to be acceptable even in large uteri. ${ }^{22,23}$ In cases of large uteri, the procedure is possible via laparoscopy. Uterus and fibroids are dissected and morcellated in situ.

In a random evaluation of 253 nonselective cases, the entire excoriated tissue cylinder specimens obtained at hysterectomy in our department were histologically reexamined. In all cases, the transitional zone from the ectocervix to the endocervix (from squamous to columnar epithelium) was completely removed. In only six cases could endocervical glands be found at the cutting margins $(2.3 \%=0.02 \%$ coincidence). If cervical carcinoma were to develop in all of these cases, the incidence rate of cervical carcinoma post CISH would be 0.02 cases per 100,000 , which is a frequency of 1:5,000,000.

\section{Laparoscopic Supracervical Hysterectomy}

Prerequisites for LASH are the absence of premalignant and malignant alterations within the cervix and the uterine body and indications are bleeding abnormalities, pain, uterine fibroids, and adenomyosis. The LASH operation is technically simple, carries less risks than vaginal or abdominal hysterectomy, and the essential connective tissue structures and the pelvic floor remain unchanged. The retention of sexual feeling and less risk of later descensus of organs or urinary incontinence, compared with total hysterectomy, are important factors in patients' decision for this procedure.

Only a few reusable instruments are used for the LASH procedure. In addition to the optic trocar and three $5 \mathrm{~mm}$ trocars, standard instruments include the bipolar coagulation clamp, scissors, 3 to 4 grasping forceps, a needle holder, a unipolar hook, and a suction irrigation system (Fig. 8).

To mobilize the uterus, the round ligaments, the fallopian tubes, and the ovarian ligaments are coagulated with bipolar forceps and subsequently dissected with endoscopic scissors. At each procedure the uterus is pulled to the contralateral side, and the ovaries and fallopian tubes are separated from the pelvic side wall or the uterus. The bladder peritoneum is delineated and the bladder pushed downward. Once the uterine vessels have been identified, they are coagulated with bipolar forceps and dissected. Hemostasis can be performed with plasma fusion, ligasure, or ultracision. The bladder peritoneum is again mobilized and pushed down cranially to where the sacrouterine ligaments leave the cervix. For the resection of the uterine body from the cervix, a monopolar hook is used. Starting from the left, the uterus is held against the anterior abdominal wall with grasping forceps and pulled toward the postcranial side. From the right, the dissection is carried out step-by-step with the unipolar hook. After appropriate hemostasis in the area of the cervical stump, bipolar coagulation of the cervical canal is performed. The uterus itself is morcellated. The peritoneum can be left open; however, it can also be closed over the cervical stump. Since the introduction of the cutting loops by Karl Storz, LINA, and other companies, the cervix is easily separated from the uterine body by these monopolar loops. 

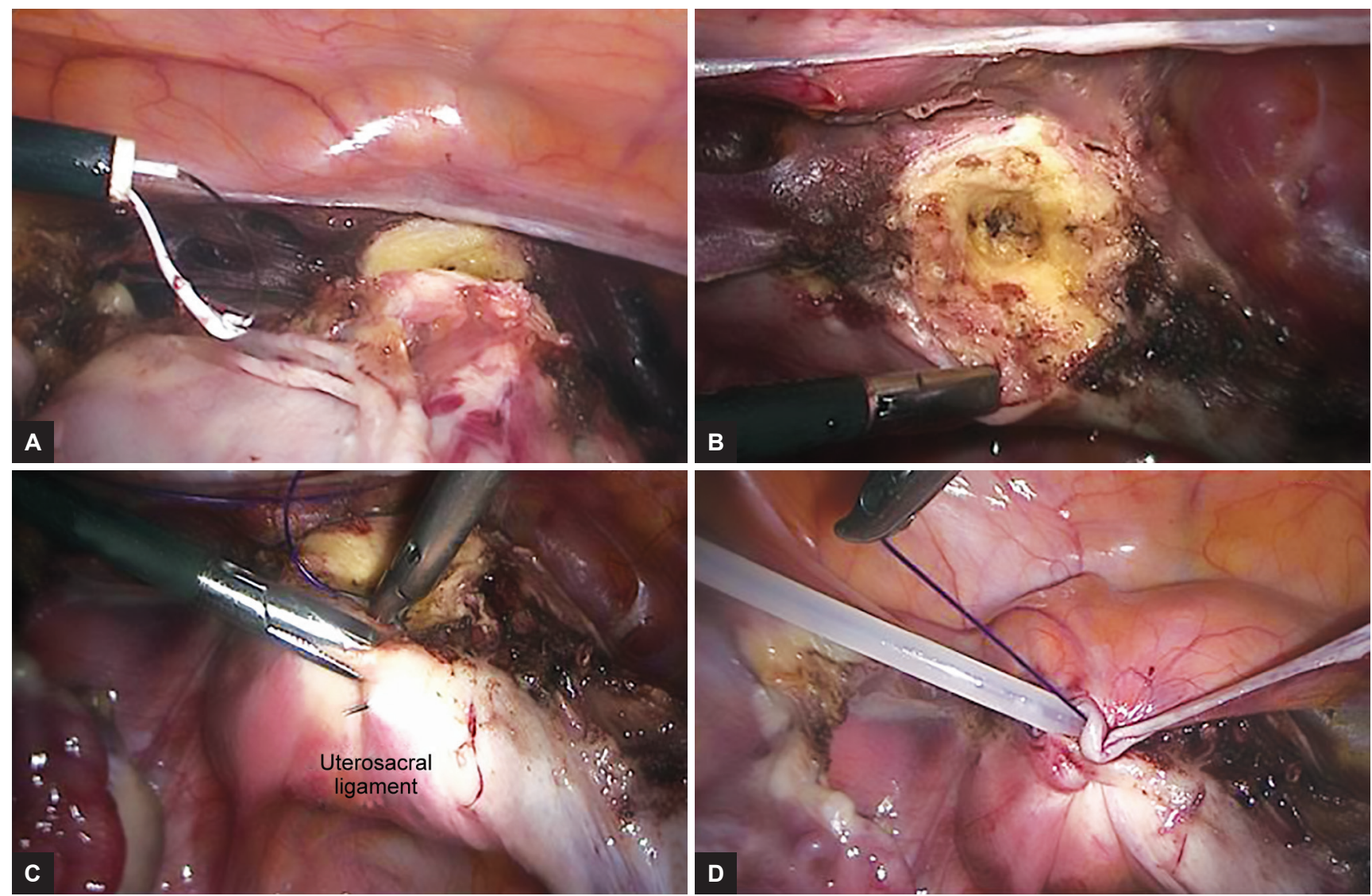

Figs 8A to D: LASH procedure with dissection of uterine body from vagina using the STORZ loop (endoscopic monopolar loop for sectioning of uterus) ligation technique in three steps. (A) Loop placed around the cervix. (B) Cervical stump after separation from the uterine body. ( $C$ and $D$ ) Peritonealization

To be able to remove the uterus, we first widen the incision and bring in one of the conventional morcellators (STORZ ${ }^{\circledR}$ or others). At the end of the operation, lavage is performed and the cervical stump is checked. Within the last 3 years, more than 500 LASH procedures have been performed at the Kiel University Department of Obstetrics and Gynecology without any complications. Cervical endometriosis and rectovaginal endometriosis do not represent indications for LASH. ${ }^{10,24}$

\section{CRITICAL SUMMARY}

A laparoscopic CISH or LASH procedure is possible even in cases of uterine fibroids, larger than the 24th gestational week in size. Taking into account the remaining cervical concept, a laparotomic subtotal hysterectomy is an alternative procedure for larger fibroids. At LASH in comparison to CISH the coring of the inner cervix is replaced by bipolar coagulation of the cervical canal via laparoscopy. Laparoscopic subtotal hysterectomy is an ongoing technique in patients that can be checked regularly by their gynecologist. We do not advise it for patients who do not come back for annual gynecological controls.

The surgical benefits are:

- Secure transvaginal coring out of the cervical mucosa including the glandular component or coagulation
- Preservation of the cardinal ligament

- Preservation of the pericervical network of nerves

- Protection of the ureters, uterine artery, bladder and rectum, etc.

- No colpotomy

- The vagina is not shortened

- No danger of abdominal infection through contamination from vaginal bacteria

- Elimination of the method associated secondary healing of the vaginal cuff

- Minimal traumatization and little blood loss

- Elective suspension of the ligaments on the cervical fascial stump as opposed to the vaginal cuff The medical benefits are:

- Prophylaxis against cervical stump carcinoma

- Complete preservation of the pelvic floor anatomy through preservation of the support function of the cardinal ligament

- Reduced physical stress for the patient

- Reduction in the time for reconvalescence

- Complete preservation of sexual function with regard to subjective vaginal and cervical components

- Complete preservation of the functionability of the vagina as regards partner contact

- Earlier return to sexual activity 
- No change in the perception of sexual contact by the partner

- Better quality of life through LASH despite hysterectomy

The standardized LASH minimally invasive surgical technique is simple to learn and can be performed with a few simple endoscopic surgical instruments. The special significance of the LASH procedure is that it can be performed on nulliparous patients, patients who have not previously had a vaginal delivery, and patients who have had previous surgery. The LASH provides a minimally invasive alternative to all other methods of total hysterectomy in benign conditions and has a low perioperative morbidity rate.

The LASH remains to be an effective alternative to laparoscopic total hysterectomy with the necessity of regular gynecological checks of our patients.

\section{REFERENCES}

1. Freund WA. Bemerkungen zu meiner Methode der Utuerusextirpation. Zbl Gynäkol 1878;2:497-500.

2. Tervilä I. Carcinoma of the cervical stump. Acta Obstet Gynecol Scand 1963;42:200.

3. Semm K. Hysterektomie per laparotomiam oder per pelviscopiam. Geburtsh Frauenheilk 1991;51:996-1003.

4. Semm K. Morzellieren und Nähen per pelviskopiam-kein problem mehr. Geburtsh Frauenheilk 1991 Oct;51(10):843-846.

5. Mettler L, Semm K, Shah A, Shah P. Intrafascial supracervical hysterectomy without colpotomy and transuterine mucosal resection by pelviscopy and laparotomy—our first 200 cases. Curr Invest Gynecol Obstet 1993;9:359-362.

6. Mettler L, Semm K, Lüttges J, Panadicar D. Pelviskopische intrafasciale Hysterectomie ohne Kolpotomie (CISH). Gynäkol Prax 1993;17:509-526.

7. Semm K. Prophylaxe der Sterilität durch minimal invasive Chirurgie. Der Frauenarzt 1994;35:944-954.

8. Mettler L, Alvarez-Rodas E, Lehmann-WillenbrockE, Lüttges J, Semm K. Intrafascial supracervical hysterectomy without colpotomy and transuterine mucosal resection by pelviscopy and laparotomy. Diagn Therap Endosco 1995 Feb;1(4): 201-207.

9. Mettler L, Semm K, Lehmann Willenbrock E, Shah A, Shah P, Sharma R. Comparative evaluation of classical intrafascial supracervical hysterectomy (CISH) with transuterine mucosal resection as performed by pelviscopy and laparotomy-our first 200 cases. Surg Endosc 1995 Apr;9(4):418-423.
10. Alkatout, I.; Mettler, L.; editors. Hysterecotomy: a comprehensive surgical approach. 1st ed. Vol. 33. Switzerland: Springer International Publishing; 2018. p. 1639.

11. Donnez J, Nisolle M. Laparoscopic supracervical (subtotal) hysterectomy (LASH). J Gynecol Surg 1993 Summer;9(2):91-94.

12. Lyons TL. Laparoscopic supracervical hysterectomy. A comparison of morbidity and mortality results with laparoscopically assisted vaginal hysterectomy. J Reprod Med 1993 Oct;38(10):763-767.

13. Mettler L, Semm K. Subtotal versus total laparoscopic hysterectomy. Acta Obstet Gynecol Scand 1997;164:88-93.

14. Kim DH, Bae DH, Hur M, Kim SH. Comparison of classic intrafascial supracervical hysterectomy with total laparoscopic and laparoscopic-assisted vaginal hysterectomy. J Am Assoc Gynecol Laparosc 1998 Aug;5(3):253-260.

15. Lyons TL. Laparoscopic supracervical hysterectomy. Obstet Gynecol Clin North Am 2000 Jun;27(2):441-450, ix.

16. Okaro EO, Jones KD, Sutton C. Long term outcome following laparoscopic supracervical hysterectomy. BJOG 2001 Oct;108(10):1017-1020.

17. Morrison JE Jr, Jacobs VR. 437 classic intrafascial supracervical hysterectomies in 8 years. J Am Assoc Gynecol Laparosc 2001 Nov;8(4):558-567.

18. Milad MP, Morrison K, Sokol A, Miller D, Kirkpatrick L. A comparison of laparoscopic supracervical hysterectomy vs laparoscopically assisted vaginal hysterectomy. Surg Endosc 2001 Mar;15(3):286-288.

19. Mettler, L. Manual for laparoscopic and hysteroscopic gynecological surgery. New Delhi: Jaypee Brothers Medical Publishers (P) Ltd; 2006.

20. Salfelder A, Lueken RP, Bormann C, Gallinat A, Moeller CP, Busche D, Nugent W, Kruger E, Nugent A, Scotland V. Die suprazervikale Hysterektomie in neuem Licht. Wiederentdeckung als minimalinvasive Methode. Frauenarzt 2003;44(10):1071-1075.

21. Bojahr B, Raatz D, Schonleber G, Abri C, Ohlinger R. Perioperative complication rate in 1706 patients after a standardized laparoscopic supracervical hysterectomy technique. J Minim Invasive Gynecol 2006 May-Jun;13(3):183-189.

22. Lyons TL, Adolph AJ, Winer WK. Laparoscopic supracervical hysterectomy for the large uterus. J Am Assoc Gynecol Laparosc 2004 May;11(2):170-174.

23. Learman LA, Summitt RL Jr, Varner RE, McNeeley SG, Goodman-Gruen D, Richter HE, Lin F, Showstack J, Ireland CC, Vittinghoff E, et al. A randomized comparison of total or supracervical hysterectomy: surgical complications and clinical outcome. Obstet Gynecol 2003 Sep;102(3):453-462.

24. Mettler, L.; Alkatout, I.; Keckstein, J.; Meinhold-Heerlein, I.; editors. Endometriosis: a concise practical guide to current diagnosis and treatment. 1st ed. Tuttlingen: Endo Press $\mathrm{GmbH}$; 2017. 